\title{
Re-Ornament of Traditional Architectural Ornament and at the Present-Time the Possibilities of Technology
}

\author{
Bugu Sah \\ American University of Cyprus, Lefkosa, TRNC \\ E-mail: b.sah@auc.edu.tr \\ Zarif Ezdesir \\ Self-Employed, Hatay, Turkey \\ E-mail: zarifezdesir@outlook.com
}

\begin{abstract}
Throughout the history of architecture, ornamentation has been applied as elements that embody emotions through aesthetic pursuits within the scope of the possibilities, and techniques of the period. Traditional craftsmanship in ornamentation are items embodied in architectural structures in historic buildings by local craftsmen. Its protection necessitates the method of transmission from generation to generation. In traditional production times, this transmission was handled by competent people. At the present-time, technological developments have caused a radical change during this regard. This study aims to enhance how the ornaments in traditional architecture are often revitalized and interpreted by applying a re-ornamental understanding of contemporary architecture and benefiting from the possibilities of technology.
\end{abstract}

Keywords: Architectural Ornament, Re-Ornament, Technology, Tradition

DOI: $10.7176 / \mathrm{JSTR} / 7-05-03$

\section{Introduction}

Ornament as an ornamental element is often described as an additive to an ornament a superior and functional object. Ornaments are the main sources of human visual cultures; hence, it is related to individual identity, and hence the identity of the community (McNicholas, 2006:5). The ornamentation acts as a bridge connecting the building with the environment, connecting people with history and culture. An ornament, as an ornamental item, is usually described as an additive to ornament superior, a functional object (Bais, 2016:23). Building ornamentation has been done since people started quoting religious books using certain patterns, symbols, geometric shapes, and alphabets on the surfaces of architectural elements and other objects. These symbols and shapes were then used because the identity of individuals living during a particular environment, and as a time went on, people began to form some changes within the ornamentation due to certain factors like the change of existing materials, a world influence, cultural changes.

The patterns within the ornamentation define many cultures and regions with their physical characteristics. The ornament also can be expressed in three dimensions, as a two-dimensional art, by using colours or by carving surfaces using geometric shapes. The ornament has become an art that speaks without the necessity for words while describing the days it existed.

Period materials such as stone, brick, tile, ceramics, and glass were used for ornamentation, and ornamentation was obtained with the natural colour and structure characteristics of the material and the arrangements obtained by closing it later (Aydın, 2009:1).

The effect of technology, development has accelerated with the 21 st century, on production processes has manifested itself in all disciplines, and in the field of architecture. After 2000, both rapid changes in computer technology and the new form-resource understanding of architecture caused concepts such as algorithmic, parametric and evolutionary design to spread and be used by many architects. (Şekerci, 2020:37).

It is in search of the proper place to exist among or additionally to several inputs like an ornament,

28 | P a g e

www.iiste.org 
surface, material, style, technology, location, structure and therefore the influence of mass. At the present-time, the art of ornamentation moves in several directions from its design to its production, more conceptually and abstractly as an evolutionary product of digital technologies.

Ornamentation may be a purely visual form and may therefore be evaluated from an aesthetic point of view. Might say that the essential sort of architectural taste and therefore the task of the architect is to create something that's both eye-pleasing and functional. counting on the architecture, ornamentation is seen in several ways.

The ornament is often obtained using different materials. for instance, ornaments are often provided while making walls with different colours and arrangements for building products like stone and brick. Another is that the ornamentation made on the facade of the building later. Covering the wall faces with different materials, shaped plaster, wood, etc. Trying to beautify with is an example of the sort that depends on the architecture and is formed later. By revealing the transformation from traditional to contemporary in architecture, different ornaments designed on the surfaces of the architectural elements of the buildings are going to be examined. Basing the planning on tradition and referencing it from there. The contemporary re-ornamentation of tradition is that the extension which will bring it to this by inspiring instead of copying.

\section{Findings and Discussion}

In architecture, ornamentation is used to create a more attractive part of the building, or an object by adding decorative details or features. Since ornamentation is a process of adding elements to a work of art to reinforce its aesthetic features, and thus the depth and clarity of its symbolic results, it is used by every culture as an integral part of the artwork (Mitrache, 2012:567).

Ornament is produced by various individuals, architects, artists, and craftsmen. This study follows a path suitable for contemporary architecture by making use of the possibilities of technology regarding the transition of ornamentation from traditional to contemporary samples, and an innovative ornamentation approach. In traditional settings, traditional craftsmanship is completely the product of the master.

The master has knowledge and skill in using the products that are used and which are the building materials of the period. With the emergence of new and different systems due to the materials, and techniques used in contemporary architectural applications, it has been difficult to maintain the building traditions. At this point, breaking the traditional form, and its usability in a new form and a function will be discussed.

It is based on the assumption that it has a different meaning from its location regarding a material, a cultural structure and economic conditions, and that it is a manageable phenomenon. It is based on the hypothesis that it can exist with a different richness without losing anything regarding the form, a material and a displacement it is used. In this context, the relevant literature was scanned, interpreted within the desired a framework within the available information, and as a result of the analysis and evaluations, predictions were made about what kind of technology can be reinterpreted. It has been tried to compare the techniques used in the past with the techniques that can be used in today's technology and to make an evaluation at that rate.

\section{Definition of Ornament, History and Ornamentation in Architecture}

Etymologically, the ornament has been explained as follows with different definitions that have the same meanings:

It is described in English dictionaries as a "useful accessory that gives elegance or beauty" (Merriam Webster, 2020: merriam-webster.com).

It has been the word derived from "ornement" in Old French and "Ornamnetum" in Latin (Online Etymology Dictionary, 2020: www.etymonline.com).

It is to an ornament the basic elements of the building with two- and three-dimensional shapes, patterns, and colours that their functions do not require, sometimes even to some extent. It is an art form formed by the combination of ornamental motifs in a search of a specific form (Kuban, 2007:207). The art of ornamentation has developed consistent with cultures and time and has become a sort of introducing and expressing the personality of societies over period. The ornament shows the historical, and cultural values of the society in a certain era. It goes from an architectural communication to provide the identity of the building, and thus the whole community through an organized expression process (Bothireddy, 2007:5).

In Egyptian art, ornamentation, which features a religious purpose generally, was replaced by the

29 | P a g e

www.iiste.org 
outward-looking a tradition of architecture and ornamentation by the Mesopotamian people, who led an earthly way of life. The art of ornamentation, which developed greatly within the Greek, Roman, and Byzantine periods, enabled civilizations to express themselves with different architectural styles and forms in many parts of Europe within the Middle Ages. Although influences from Antiquity, ancient Persian and Central Asian art are seen in Islamic architecture and ornamentation, they have found their own elegance over time. With the rise of more advanced civilizations, ornaments based on natural beings or abstract geometric forms are seen in ancient Egypt, Mesopotamia, and the Mediterranean civilizations. Some ornaments have the feature of being used both in a certain historical period and in certain parts of the building. Mesopotamian artists generally used, herbal, themed ornaments, lotus flower and opened daisy friezes are made of buttons and flowers with composite tiles and used for flooring.

In the prehistoric ornamental forms, the first objects that ornamentation appear are pottery (Ünsal, 1973: 229). Especially in geometric ornaments, the dialectic of the material in nature, the original structure of the material and the (functionalist) views based on the techniques (Mülayim) are determined. Different understandings emerged from both the content and the formal structure of the ornaments; It is mostly based on religious-philosophical, symbolic, political thought and a worldview. Also, the notion that the shapes suggested for ornamentation has a certain value in various settings are often added (Mülayim, 2002:221).

The idea of decoration, called ornaments specific to the structure's function or materials, emerged in the mid-20th century. Architectural ornamentation is highly dependent on the building materials of the building. Ornaments are created on the structure of the building by carving and chipping. Stone and wood are the most suitable materials for these processes. Another factor affecting the architectural decoration is the intellectual environment. Buildings can create their forms by being influenced by beliefs and objects ranging from polytheistic religions to Islam. Architectural decoration is the balance between building and human. In the historical process, it has emerged with the concepts of aesthetics, decoration, symbolization and enrichment. It is used in architecture to reveal and dominate a more attractive part of the building or object by adding ornamentation, decorative details or features.

Ancient Egyptian culture was probably the first to add pure ornamentation to their buildings. They shaped their decorations inspired by nature and papyrus. (Riegl, 1992: 218).

The creative values that form the essence of the space, such as the monuments that make up the memory of humanity, municipal architectural structures, the rituals performed in these buildings and spaces, and exceptional traditional concepts, are the common starting point in influencing the future of societies. Ornament also plays an important role in showing the historical, and cultural values of a society. As a way of architectural communication, ornamentation provides an identity to the individual and therefore to society.

The ornamentation shows the social status, talks about the differences between the people, and the class he belongs to. Additionally, reveal the class difference, they also refer to the sectarian differences of multi-religious sects (Massey, 2013: 497).

\section{Ornamentation in Contemporary Architecture and Re-Ornamental Approaches}

Each successive style was a modification and an alteration of a previous architectural design. The idea of creating a sight played a really important role, so, it is worth understanding the meaning of the term, something of a striking or impressive kind, something of remarkable nature, public performance, or a display - especially on a large or lavish scale.

Parametric figuration is probably the most determined form of architectural articulation. To be effective, it must go beyond just visual effects (Schumacher, 2009: 34).

Pattern is the back pattern, one of the main incarnations of ornamentation: patterned colors, patterned materials, and assemblies (Levit, 2008: 8). Ornaments in contemporary architecture contribute to the image and commercial marketing. An existing culture has been created by the dominance of images over architecture. These ornamentations took the attention of the public in contemporary architecture in the age of visual communication. (Balık and Allmer, 2016: 167).

With the latest technologies used, we can say that there is a significant return to classical ornaments.

Throughout history, geometric patterns have formed an important part of art and ornamental design. Today we have unprecedented ability to understand ornamental styles of the past, to recreate traditional designs, and to innovate with new interpretations of old styles and with new styles altogether (Kaplan, 2002:7).

The relationship between an ornament and architecture has taken an interesting course through out

30 | P a g e

www.iiste.org 
history. It was sometimes exposed in the form of a mere expression and sometimes as a show of supremacy. During its course of development, the concept of ornamentation has evolved from cave carvings to technical perfection and a photo mounting of new constructions (Sağlam, 2013:127). Buildings can be observed from various points of a view, as well as from different scales and distances, which makes the reveal different ornamental scopes. The contemporary application of an ornament like a structural and a digital ornament proposes innovative aspects the maximum amount because it recreates the normal applications of a culture, a brand, a function, a context, or power. It is open to interpretation. Attracting the public and presenting a spectacle is one of the main purposes of applying an ornament in contemporary architecture (Pietrzak). It is usually between these two states when conjuring a memory. It is an intellectual time travel between history (the past) and reality (the present). Humans always desire to relive their memories in the present, for that reason it is perfectly normal to recall moments from their youth and reflect on the past. This condition does not allow us to differentiate reality and history, and when interpreted architecturally, creates a scenario in which historic and contemporary architecture must be carefully assessed (Pietzrak, 2011:11).

At the beginning of the 20th century Ornament populism was decreasing because it did not fit modernism's progressively rationalizing perspective. Adolf Loos described ornament as waste of money and labor-intensive, as the style would change whilst pure form did not.

Although ornamentation never completely disappeared from modern history, it did change significantly within a short period as artists and architects reacted against the status quo. The early era of the modern movement was concerned with the task of presenting the truth of materiality and proving how less could be more. Managed to abstract ornamentation into a reflection of our modern culture, then we should be able to reconsider its role in a design, as something more than an extra-budgetary expense.

Local, contextual and symbolic, architectural; It was losing its importance due to the standardization of details in globalization. Contrary to traditional understandings, ornamentation in contemporary architecture begins to transform into virtual reality through digital media. There is a wide range of ornaments from architectural details to urban texture. Moreover, in contemporary architecture, ornamentation can be applied from a graphic composition to a flat image, from a relief to a threedimensional structure. Using technology as a tool enables experimental work with ornamentation, form, structure and surface in contemporary architecture.

Antoine Picon (2013) in his book Ornament, the Politics of Architecture and Subjectivity; Explore the features of ornamentation in the history of architecture and the limits of ornamentation in contemporary architecture.

Picon contends that the ornament loses its political and subjective aspects while symbolizing the client's social position or carrying the architect's private brands. Contemporary emergence of ornamentation, especially CNC milling, laser cutting, advocates that it has made a rise with threedimensional printing techniques.

Andrea Gleiniger and Georg Vrachliotis analyze the pattern and ornament in the digital technology age in the book Pattern: Ornament, Structure and Behavior. Gleiniger and Vrachliotis (2009) argue that, like the other four designers, the new decoration emerging using digital technology is due to the pattern and pattern formation (Balık and Allmer, 2016: 162).

One of the leading names in German expressionist architecture, Hans Poelzig states in his article published in 1906, that era has created a selected sort of his own in every field that concerns ornament (Ulrich, 1991:4).

\section{The Place of Technology in the Re-Ornamentation}

The introduction of digital technology into our lives has caused many lifestyle changes. The product, which was created through calculations and drawings made by a hand in the past, is now created by considering many stages together thanks to the ease of calculating variable parameters in the light of the computer-aided a design (Şekerci, 2020:52).

Theoretical, perceptual, and formal/geometric changes and transformations that occur in architectural design products and spaces are investigated through the element of "experience" by associating them with developments in architectural design tools and technologies. It is aimed to understand the mechanisms of the architectural design problem that affect and guide the experience of the designer, and to establish an evaluation framework and to develop an understanding of the effects on products for the development of design tools and Technologies (Atılgan, 2006:6).

In the developing architectural design tools and technologies, the most characteristic feature of digital technologies, different from previous tools, is the ability to identify objects, movements, and different

31 | P a g e

www.iiste.org 
phenomena and to express them numerically, with the ability to metaphorize almost any subject and transfer it to form (Atılgan, 2006:155).

We have new algorithmic tools: computers and the abstract mathematical processing they enable allow us to perform calculations that were intractable in previous generations. Finally, we have technological tools: manufacturing devices that can turn a synthetic description provided by a computer into a realworld artifact.

Taken together, these three sets of tools provide new opportunities for the application of computers to the analysis and creation of ornament (Kaplan, 2002:7).

Design tools and technologies mediate the designer in the process between his ideas about design and his production. With the transition from analogue technologies to digital technologies, the increasing power of design technologies has transformed design products with the opportunities of modelling and manufacturability, which is an important technique in overcoming the problems related to design experience. A return to ornamentation and ornamentation in contemporary architectural theory and practise is closely related to mastering digital developments and advanced technology.

There has been a transition from analogue to digital in the production of decoration. In this context, it started to be produced sometimes as completely digital and virtual, and sometimes as a combination of digital and analogue. Although Loos sees ornamentation as a waste of labour and time, in contemporary architecture, ornamentation has become economically convenient and easily available thanks to mass production techniques.

It was felt there was a lack of environments where people could integrate more complex relationships with geometries, and design them, and this deficiency was tried to be overcome with the development of computer-aided parametric modelling tools after many years (Şekerci, 2020:31).

Over time, it has enabled the development of such software and hardware in the field of technology, opening the way for three-dimensional drawings. Subsequently, modelling tools that serve specific purposes and processes of the design began to be offered to the user (Şekerci, 2020:27).

While moving from analogue to digital technologies, the first of the two most important factors bringing change in design processes has been the increased possibilities of manufacturability and the trust in the connection with reality.

From Vitrivius' architect, who painted the columns into blue, to Mies van der Rohe, who designed elegant steel columns, or to Herzog \& de Meuron, who made designs of technological wonders during a digital era, the sole change has taken place within the placement of the concepts of "beauty" and "meaning" as different categories within architectural design. As being the foremost instigating character of the age, the thought that Loos aimed toward not attributing architecture or art with an essence or autonomy, but that he wanted to supply the space that every sort of practice must improve itself and for cultural mobility points to a replacement field of study (Foster, 2004:10).

The contemporary emergence of ornament in parallel with the new construction and manufacturing technologies, specifically $\mathrm{CNC}$ milling, laser-cutting, three-dimensional printing, and robotic layering. Dwelling on the topics of the algorithm, behavioural pattern, neuroscientific pattern, and musical pattern, the authors investigate global expansions of ornament in the digital age. Technologies like 3D-printing, CNC milling, 3D-milling offer the possibility of change vis-a-vis ornament in practice.

Unlike standardized machine mass-produced elements, these new technologies are capable of manufacturing 'mass-customized' elements. During the design phase, these elements can be optimized by software to be ergonomically and economically designed and, relating to Loos, hence these designs would not become waste of material or labour in their final state.

The continuity of the stages of the design processes with the modelling technique and the manufacturability that comes with the computational power has made the design process, which is an actively managed remotely in analogue design tools and processes, into "direct" action in a digital environment. The third difference from the analogues of digital design tools, which are tools with high processing and conceptual power, is the ability to digitize. Any measurable phenomenon that will be associated with the design in some way with the digitization technique can be transferred to the design environment. Being able to produce metaphors and metaphor is a feature peculiar to computers that differs from analogue Technologies (Atılgan, 2006:214).

Architect Frank Gehry, who has been interested in CAD technology since 1989, stated that the CAD program will affect not only in the field of design but also in engineering science. Thanks to the CAD program, two-dimensional and three-dimensional drawings can be made. Thanks to the program, the design can be shaped, detailed and produced. The program offers its users specific and flexible design opportunities and enables analysis and simulations (Şekerci, 2020:31).

32 | P a g e

www.iiste.org 
It is aimed to explain how to make it functional in a new form by drawing attention to architectural ornamentation values. The issue of how to design with lighter materials with a new material other than traditional materials is also emphasized based on locally used materials.

The rising a mentality of efficiency that machinery brought to civilization would also not coincide with the labour-intensive mastery of an ornament. With the efficiency and the technological advancements of machinery and mass production, standardization found its role in architecture (Bergeijk, 2013:153).

From another angle, it is also a remarkable point of how geometric forms can be used by making use of parametric architecture. Undoubtedly, simplicity and technological advances play an important role in our ability to create spaces that can accommodate so many different structures.

\section{Conclusion}

The methodology of reinterpreting ornamentation with an innovative approach includes the reconstruction of the past with new perspectives and interpretations. The purpose and scope of this work are to reveal the need to create a re-ornamentation expression as a form of relationship between discourse and architectural practice. The method initiative, which can be seen as a new expression and concept dynamic, is the desire to express architectural thought and reveal it in different forms. Innovative approaches to ornamentation generally refer to the order in forming the form.

Contemporary form approaches aim to present a large number of alternative or changeable designs by conceptually evaluating the groups that shape the design, unlike traditional form approaches. At the present-time, the re-ornamentation to ornamentation can appear in different aspects as products that can be developed with digital technologies.

Over time, the ornamentation lost its importance and was called a loss. But the ornament, which has always managed to preserve its pure form, continued to add various flavors with the same effect to the senses. The dramatically changing ornament is today a serious example of how it can be created from least to most.

Ornament, which can vary from architectural detail to urban texture, continues to be applied to contemporary architecture in another story, internally or externally. The ornament has gained a model without specifying its symbolic significance. The components that make up the traditional ornamentation are the specific situation, the ease of use of the material, the social and public activities of the individuals. Once again, similar facts and contemporary and creative needs should be pursued. The research was carried out to be able to adapt ornamentation to our modern culture without an illusion and to reevaluate its role in the design, the progress from traditional engineering to contemporary design, the presentation of contemporary building innovation. The components that make up the traditional ornamentation are the specific situation, the ease of use of the material, the social and public activities of the individuals. Once again, similar facts and contemporary and creative needs should be pursued. It was tried to understand how to decide on the process that shaped the design in the design phase, how the data of the developed design was transformed in the production phase and how it will affect this new formation.

\section{References}

Atılgan, D. (2006) Gelişen Tasarım Araç ve Teknolojilerinin Mimari Tasarım Ürünleri Üzerindeki Etkileri. PhD Thesis, Dokuz Eylül University Institute of Science.

Aydın, D. (2009) Bina bezeme malzemelerinin uygulamadaki konumu ve yitirilen görsel kalite. Master's Thesis, Selcuk University Institute of Social Sciences.

Bais, J. (2016) Democracy in architecture: the revival of ornament. Theory Thesis, Delft University of Technology.

Balık, D. \& Allmer, A. (2016, Mart). A critical review of ornament in contemporary architectural theory and practice. ITUJFA, 18, 157-169

Bergeijk, H. van (Ed.). (2013). Aesthetic economy. Objectivity in Dutch architecture. Delft: BBA Publishers. 
Bothireddy, H. (2007). Syntactic and semantic role of ornament in architecture. Master's Thesis, University of Cincinnati.

Foster, H. (2004). Tasarım ve Suç. İstanbul: İletişim Publishing.

Kaplan, C. S. (2002). Computer Graphics and Geometric Ornamental Design. PhD Thesis. University of Washington Graduate School.

Kuban, D. (2007). Osmanlı mimarisi. İstanbul: YEM Publishing.

Levit, R. (2008). Contemporary ornament: The return of the symbolic repressed. Harvard Design Magazine, 28, 1-8.

Loos, A. (2019). Mimarlık üzerine. (A.Tümertekin- N.Ülner, tr.). İstanbul: Janus Publishing. (Original publication date 1929.)

Massey, J. (2013). Ornament and decoration. In G. Brooker \& L. Weinthal (Eds.), The Handbook of Interior Architecture and Design. A\&C Black.

McNicholas, M.T. (2006). The relevance and transcendence of ornament: A new public high school for the South Side of Chicago. Master's Thesis, Indiana University of Notre Dame.

Mitrache, A. (2012). Ornamental art and architectural decoration. Procedia-Social and Behavioral Sciences, 51, 567-572.

Mülayim, S. (2002). Anadolu Türk mimarisinde geometrik süslemeler. Ankara: Publication of the Ministry of Culture and Tourism.

Online Etymology Dictionary. Definition of ornament. Access March 2020. https://www.etymonline.com/search?q=ornament

Ornament | Definition of Ornament by Merriam-Webster. Access April 2020. merriam-webster.com

Picon, A. (2013). Ornament: The politics of architecture and subjectivity. UK: WILEY.

Pietrzak, R. (2011) Re-ornamentation. Master's Thesis. Azrieli School of Architecture and Urbanism Ottawa Canada.

Riegl, A. (1992). Problems of Style: Foundations for a History of Ornament. (E.Kain, tr.). (Original publication date 1893.)

Sağlam, H. (2013). Re-thinking the Concept of "Ornament” in Architectural Design. 2nd World Conference on Design, Arts and Education DAE-2013 Procedia-Social and Behavioral Sciences 122 (2014) $126-133$.

Şekerci, C. (2020). Parametrik Tasarım Yaklaşımııın Iç Mimarlık Ĕgitimine Katkısı. PhD Thesis. Hacettepe University Institute of Fine Arts.

Schumacher, P. (2009). Parametric patterns. Architectural Design, 79(6), 28-41.

Ulrich, C. (1991). Programs and Manifestoes on 20th-Century Architecture. (ed.)

Vitruvius. (1960). The ten books on architecture. (M.H. Morgan, tr.) New York: Dover Publications (Original publication date 1914.) 